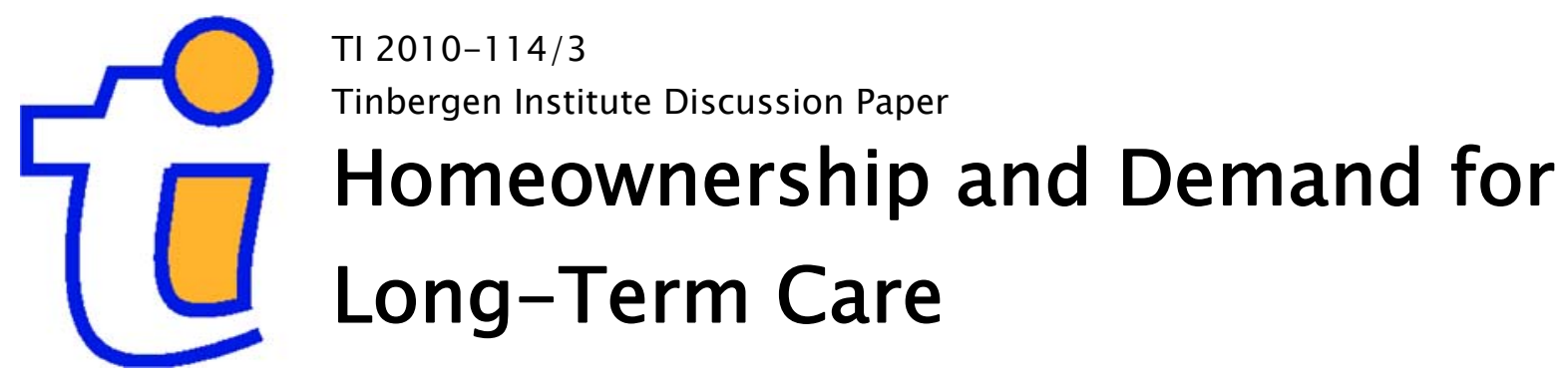

Jan Rouwendal*

Fleur Thomese

VU University Amsterdam.

* Tinbergen Institute. 


\section{Tinbergen Institute}

The Tinbergen Institute is the institute for economic research of the Erasmus Universiteit Rotterdam, Universiteit van Amsterdam, and Vrije Universiteit Amsterdam.

Tinbergen Institute Amsterdam

Roetersstraat 31

1018 WB Amsterdam

The Netherlands

Tel.: +31(0)205513500

Fax: $+31(0) 205513555$

Tinbergen Institute Rotterdam

Burg. Oudlaan 50

3062 PA Rotterdam

The Netherlands

Tel.: + $31(0) 104088900$

Fax: $+31(0) 104089031$

Most TI discussion papers can be downloaded at http://www.tinbergen.nl. 


\title{
Homeownership and demand for long-term care
}

\author{
Jan Rouwendal ${ }^{*}$ and Fleur Thomese T) $^{* *}$
}

Key words: home equity, health care, ageing, housing tenure, institutionalization

\begin{abstract}
Elderly home-owners get institutionalized less often than renters do. We hypothesize that housing tenure itself explains this behavior. Using longitudinal data from a Dutch community sample ( $\mathrm{N}=$ 2,372) collected between 1992 and 2005, we find a negative effect of housing tenure on the probability of moving to a nursing home between two subsequent waves. This effect remains significant after controlling for health, socio-economic status and the presence of a partner and or children. We could not reduce this finding to a variety of explanations directly related to housing tenure. There was no substantial effect of higher payments for long-term care for wealthy people before 1997. Neither did we find evidence that home owners have a strategic bequest motive, and use their house to attract informal care from their children. We do find that homeowners use informal care-at-home to postpone or avoid institutionalization. Homeowners do not appear to live in houses more suitable to the needs of old age than renters, they do not have better social networks from which they can recruit informal caregivers. However, they express a greater satisfaction with their housing situation than renters, even if their health deteriorates. We therefore interpret our findings as the result of a strong desire among homeowners to stay where they are - in their own property - and better possibilities they have - as owners - to realize this desire.
\end{abstract}

\footnotetext{
${ }^{*}$ Department of Spatial Economics, Faculty of Economic Science, VU University De Boelelaan De Boelelaan 1105, 1081 HV Amsterdam Phone: 31-205986093 Fax: 31-205986004 Email: jrouwendal@ feweb.vu.nl

${ }^{* *}$ Department of Sociology, Faculty of Social Sciences VU University
} 



\section{Introduction}

Demand for nursing home care is expected to increase substantially over the coming decades due to population aging in many countries. Care-at-home, provided by relatives or professional caregivers, is the most important substitute for institutionalization. Many elderly like to stay in their homes as long as possible even when their health deteriorates, but there seem to be important differences in the possibilities they have for realizing this desire. In particular, it has been observed frequently that homeowners have a lower probability of becoming institutionalized than renters, also when a large number of control variables are included in the analysis (Muramatsu et al. (2007) and Gaugler et al. (2007) for the US, Breeze et al. (2008) for the UK, Nihtilä and Martikainen (2007) for Finland).

This finding is of potential interest since it suggests an external effect of housing tenure on the demand for long term health care. If there is a negative effect of homeownership on the demand for expensive institutionalized care, the ownership rates of the cohorts that will pass the 65 year threshold in the coming years may have a substantial impact on the need to provide this expensive type of care. However, if the observed relationship between housing tenure and demand for residential care would be due to confounding variables, such as a better average health status of homeowners, homeownership in itself would be of no interest for health care policy. Many existing studies of the demand for long term care use homeownership as a control variable and ignore the issue of causality. For instance, in their review of social consequences of homeownerships, Dietz and Haurin (2003) find many studies lacking from an econometric perspective. In particular, they repeatedly observe a failure to include potentially important control variables and a neglect of spurious associations between homeownership and outcome variables.

In this paper we explore the relationship between homeownership and the demand for residential care using a rich dataset that allows us to consider a wide variety of variables over time in a Dutch community sample of elderly. Our data show a substantially lower transition rate of homeowners to institutionalized care, and we investigate the robustness of this finding for the incorporation of detailed controls to parcel out compositional effects that could mistakenly be interpreted as a causal link between housing tenure and the demand for nursing home care. We also consider the impact of effects that are more closely related to ownership of the house one 
lives in: owning a substantial amount of wealth and living in more luxury housing. The former may imply a higher cost of receiving long-term care through social security or the public health care system, as well as offer the possibility to avoid institutionalization by making more intensive use of care-at-home. The latter may imply that owner-occupiers live in houses that are - on average - better suited to the needs of old age than renters.

In the next section we discuss the two groups of explanatory variables. In section 3 we make some remarks about the specificities of the Dutch situation to which our empirical work refers. Then we introduce the data and the model. In sections 5 and 6 estimation results are reported. In section 7 we investigate if homeowners rely more on intensive care provided home at home than renters. Section 8 concludes.

\section{Institutionalization and the demand for long-term-care}

The primary focus of this paper is on institutionalization in nursing homes or related institutions ${ }^{1}$ for the provision of long term care. Differences between the transition rates of homeowners and renters to nursing homes could result from compositional effects, as well as from structural reasons. Compositional effects occur when people who own their home differ in the propensity to become institutionalized for reasons that are only indirectly related to homeownership. There are many reasons why such effects may occur. We briefly discuss four of them, which are in our view the most important ones. Then we consider three possible causal mechanisms associated with homeownership that could explain the link between homeownership and lower transition rates that remains after controlling for compositional effects.

Health status is presumably the main driver of the demand for nursing home care. A wide range of physical, mental, and functional health conditions is associated with admission to long term care facilities (Fried et al., 2001; Gaugler et al., 2007; Geerlings et al., 2000 Miller and Weissert, 2000; Thomese and Broese, 2005). Since there exists a strong relationship between health and wealth at old age (Huisman et al., 2005; Broese et al., 2003) and home-owners in general are wealthier than renters, they have on average better health. Insufficient control for health may therefore easily lead to correlation between homeownership and admission to nursing

\footnotetext{
${ }^{1}$ The Netherlands have two types of institutions where long term care is provided: nursing homes and sheltered housing. The former provides the most intensive types of care. The distinction will be explained in the next section. In order to keep the terminology simple, we will refer to both types of institutions as nursing homes, unless it is clear from the context that the distinction matters.
} 
home that is not based on a causal link between the two variables. It is therefore important to control for health status.

Somewhat related to this observation is the fact that homeowners live with a partner more often than others and may also more often live closer to children ${ }^{2}$ who could provide the care that is necessary to postpone or even completely avoid the institutionalization that would otherwise be necessary. Since much long-term-care is provided by unpaid caregivers, it is important to control for this possibility as well.

A third possibility for compositional effects is that long-term care is less available in the locations where homeowners are concentrated. Even if public health care would guarantee that nursing home capacity per 1,000 inhabitants was approximately equal throughout space, differences in population density could still cause a much larger physical distance to the nearest nursing home, and this might have an impact on transition rates. Since homeowners are more often located in areas with relatively low densities, this could also lead to correlation between home ownership and transition rates. Moreover, if capacity problems occur in nursing homes, it is unlikely that these are evenly spread over space.

Finally, there is probably a relationship between the strength of neighborhood-based social networks and the elapsed duration of stay in the current house or neighborhood. Since residential mobility among homeowners is lower than that of renters, and the difference is especially large for elderly people, ${ }^{3}$ this may also give rise to a correlation between homeownership and institutionalization that is in fact caused by social network effects.

The four effects we have mentioned may of course all be present simultaneously and many datasets lack the possibility to control for all of them at once. The data used in this paper are exceptionally rich in this respect and enable us to take into account all the compositional effects mentioned above.

To the extent that the lower mobility of homeowners is indeed caused by their higher costs of realizing a residential move for owners, it may be argued that this lower mobility would more properly belong to the second class of explanations: those that are closely related to homeownership itself. Indeed, the classification we use here is somewhat arbitrary since the

\footnotetext{
${ }^{2}$ A surprisingly large number of adults live close to their parents. See Compton and Pollak (2009) for the US and Hank (2007) for European countries.

${ }^{3}$ See Rouwendal (2009), Figure 8.
} 
differences in wealth and in the possibility to leave a bequest that will be discussed below may also be present among renters. However, since many wealthy households are homeowners and the house is in most cases the most important asset of these households, there is in practice a strong relationship between wealth and homeownership and this motivates the distinction we use here. Being wealthy may have important consequences for the cost of receiving long-term care. Moreover, it opens up the possibility to attract informal care to postpone institutionalization, for instance by offering the unpaid caregivers the prospect of a bequest. We discuss both effects.

Moving to an institution may be associated with higher costs for home-owners than for renters (Dietz and Haurin, 2003). This is true in the US where low income households are able to use social security whereas those with higher incomes have to pay themselves for long-term care expenses. Also in the west-European welfare states the patient's own contribution to received (long-term) care is usually dependent on either income or wealth. Moreover, in some countries not all institutions providing long-term care are covered by the public health care system in the same way. This was the case in the Netherlands (to which our empirical work refers) until 1997. This will be discussed in more detail in the next section, since that particular policy change offers us the possibility to investigate the effect of higher cost of long term care for homeowners.

The - on average - larger wealth of home owners may not only imply a higher cost of institutionalization, it provides them also with better means to postpone or avoid this event. A possibility that has attracted some attention in the literature is that elderly people may postpone institutionalization by deliberately using the prospect of a substantial bequest as an incentive for their relatives to provide the care they need (Bernheim, Shleifer and Summers, 1985). The idea is that older people may expect something of their children or other relatives in return for the wealth they bequeath to them. The house is usually the largest asset of households, and a luxury house obviously signals a large bequest. The prospect of receiving part of the inheritance may consciously or unconsciously increase the willingness of relatives to provide services required by the older person in need of care. This could imply that children of home-owners, who are the usual beneficiaries, provide more informal care that children of renters do.

A third effect of homeownership on the transition to institutionalized care may be caused by the fact that owner occupied housing is usually of a more luxury kind than rental housing. There exists a well-established association between housing tenure and investments in home and neighborhood (Sampson, Morenoff, and Earls, 1999; Rohe and Stewart, 1996). This may play out 
in two ways. Homeowners may not only invest more in their homes at large, but also invest more in special adjustments to the house that enable them to stay in their home longer. Second, owners may feel more attached to their homes because of the stronger effort invested in the living environment, compared to renters (Redfoot, 1987).

\section{The Dutch context}

Long term care in the US context differs from acute medical care in four ways: it is care for chronic illnesses; the industry is dominated by for-profit facilities; little private long term care insurance is purchased; and much long term care is provided by unpaid caregivers, often relatives of those who receive care (Norton, 2000). Long term care in the Netherlands is also targeted to chronic illnesses, and is mostly provided by unpaid caregivers, but here the industry is dominated by not-for-profit facilities. In the Netherlands long term care is provided by the welfare state, which means that it is available to all. It is partly funded through (mandatory) collective insurance and partly from the revenues of taxes. Those who make use of the system sometimes have to pay a (limited) own contribution to its cost. The height of this contribution may depend on the receiver's income or, until 1997, wealth.

\subsection{The institutional setting}

The Netherlands is an example of a western European welfare state with substantial involvement of the government in health care. Since the 1950s a dual system of long term care evolved that lasted until 1997. Intensive types of long-term care were originally provided exclusively by what are called in Dutch verpleeghuizen, or nursing homes. Such care is very costly and difficult to provide by a private insurance system. For this reason the Dutch government decided to provide it through a collective insurance scheme. Nursing homes therefore became - in principle available to all, under the condition that a person's health condition was such that he or she qualified for this type of care.

For those in need of lower levels of care, a different type of institution evolved, the socalled verzorgingshuizen, to which we will refer as sheltered housing. Originally this sheltered housing (often provided in large apartment buildings) was designated for elderly who could in principle continue living independently, but found it convenient to be able to make use of less intensive types of care offered by the residential home, like housekeeping and the provision of 
hot meals. In the early years (until the 1960s), people had to be in good health to be allowed to enter into a sheltered housing. Those who did in principle had to pay the full cost of the care provided. However, if they at any point in time lacked the wealth to do so the public health care system provided assistance from the general means. As a consequence, entrance into sheltered housing was possible to all, but wealthy people had to pay a much higher price until they ran out of resources.

Over the years, demand for long-term care increased considerably. Substantial capacity and funding problems emerged for nursing homes and sheltered housing was used as a substitute for nursing homes in which those elderly whose needs for care were less intensive (compared to those admitted to nursing homes) could stay. Starting in the 1980s, the national government increasingly restricted admission to both types of residential care to those who were unable to receive sufficient care from other sources, mostly care at home. Although there remained a distinction between sheltered housing and nursing homes, in practice sheltered housing had become part of the public health care system. In the course of the 1990s the government reacted to this development by formally incorporating the homes-with-care into the publicly financed health care system. This happened in 1997 (Staatscourant, 1996) and from that year onwards, there was an income dependent contribution to the cost of care in both nursing homes and sheltered housing, which had effectively become nursing homes for those who needed less intensive care. Wealthy patients no longer needed to pay the full cost until most of their wealth was consumed.

The obligation for the inhabitants of sheltered housing to consume their wealth almost completely before assistance from the public health care system could be claimed was popularly known as the necessity to 'eat one's house' and was by many regarded as unfair, since it put a penalty on a prudent life style with relatively large savings throughout one's working age. When in 1997 residential homes became part of the public health system, income-dependent contributions became much lower. The cost of long-term care provided in sheltered housing thus decreased substantially for many home owners. The large costs of this type of care before 1997 may well have contributed to the lower propensity of homeowners to become institutionalized. If this hypothesis is true, this reluctance should have decreased after the policy change in 1997. 


\subsection{Admission to nursing homes}

The primary determinant for long term care is a person's health (Miller and Weissert, 2000). In principle, this care can be provided in alternative ways, the most important distinction being between care-at-home and institutionalization (see, for instance, Woittiez et al., 2009). Care-athome can be provided by professional workers, but also by unpaid caregivers, often relatives of the recipient. The availability of this substitute thus depends on a person's family and social networks as well as on the intensity of the demand for care.

Admission to nursing homes and homes-with-care in the Netherlands depends on a professional, independent assessment of the person's health and the associated need for care. ${ }^{4}$ This assessment has become increasingly dependent on the availability of care at home. Capacity problems in long term care emerged in the late 1980s and gave rise to long waiting lists for professional care in both the nursing homes and the homes-with-care. These waiting lists were an important cause for policy concern in the 1990s and early 2000s, while the problem seems to have been mitigated since then. As long as people were on a waiting list they necessarily had to rely on a substitute for residential care: professional care given at home (which is also part of the public health care system) or care provided by relatives, most typically the partner, if present and able, or adult children. Problems caused by the long lists were mitigated by giving priority to people with an acute need for receiving professional care. For some others on the waiting lists the substitute was quite satisfactory, as they refused to accept admittance in a nursing or residential home after being on the waiting list for some time (van Gameren, 2005). This suggests that, at least for a part of those who were are in need of long term care according to expert judgment, good alternatives to nursing homes were available.

\subsection{The Dutch housing market}

The Dutch housing markets differs from that in many other European countries as well as from the US through its large rental sector. According to Eurostat statistics, the percentage of homeowners among pensioners in the whole EU was $60 \%$ in 1995, as opposed to $43 \%$ among the Dutch pensioners. The share of homeowners is less than $30 \%$ for low incomes and more that $80 \%$ for high incomes (Rouwendal, 2009). This means that in the Netherlands the link between

\footnotetext{
${ }^{4}$ This was the case through the period 1992-2007 to which our data refer, although originally admission to homeswith care was open to all.
} 
Homeownership and long-term care

housing tenure (the probability of being an owner) and income is stronger than in many other countries.

Much of the rental housing is social housing owned by housing corporations (35\% of the total housing stock). Almost all rental housing is rent-controlled. Maximum allowable rents are related to the number of quality points for which a house qualifies. Location characteristics are hardly reflected in these quality points, which implies that rental housing close to the center of urban areas (like Amsterdam) is as cheap as rental housing in rural areas with the same amount floor space, number of rooms and other characteristics that are associated with quality points. There is excess demand for rental housing in many locations and especially in the urban areas. The allocation system for rental housing differs over the country, but everywhere priority is given to those most in need of affordable housing. Existing home owners do not easily qualify as such and mobility from the owner-occupied to the rental sector is therefore very limited.

\section{Data and method}

\subsection{The database}

Data come from the Longitudinal Aging Study Amsterdam (LASA, www.lasa-vu.nl). LASA is an ongoing study on physical, emotional, cognitive and social functioning of older adults, with a nationally representative sample (Deeg et al., 2002). In 1992 ( $t=0)$, interviewers questioned 3,805 respondents as part of the Living Arrangements and Social Networks of Older Adults research program (LSN; Knipscheer et al. , 1995), which used a stratified random sample of men and women born between 1908 and 1937. The oldest individuals, particularly the oldest men, were over-represented in the sample, which resulted in approximately equal numbers of men ( $n=$ $1,859)$ and women $(n=1,946)$. The sample came from population registers of eleven municipalities: the city of Amsterdam and two rural communities in the west of the Netherlands, one city and two rural communities in the south, and one city and four rural communities in the east. These regions represented the differences in religion and urbanization in the Netherlands at the time. Of the 6,107 eligible individuals in the sample, 2,302 (38\%) refused cooperation due to a lack of interest or time, and another 734 were ineligible because they were deceased or too ill or cognitively impaired to be interviewed. 
Homeownership and long-term care

In 1992-1993 $(t=1, N=3,107), 1995-1996(t=2, N=2,545), 1998-1999(t=3, N=2,076)$, 2001-2002 $(t=4, N=1,691)$, and 2005-2006 $(t=5, N=1,257)$ LASA performed follow-ups. Between 1992/3 and 2005/6, 46\% of the respondents died, 5\% were unable to participate in the study because of severe physical or mental health problems, $14 \%$ refused to be re-interviewed, and $2 \%$ could not be contacted because they moved to another country or an unknown address. In each wave, the interviewers received a four-day training course and the LASA field work manager supervised them intensively. The interviewer tape-recorded the interviews to monitor and enhance the quality of the data obtained. The interviews took between one hour and a half and two hours. Between observations, mortality was regularly determined on the basis of death registers.

We selected 2,372 respondents with at least 2 observations between 1992/3 and 2005/6, who were living independently in 1992/3, and included those who had died between waves. Measurement differences between 1992 and 1992/93 precluded using the first wave $(t=0)$. We will refer to the 1992/93 wave as $\mathrm{t}=1$ or wave 1 , and so on. We have at most four observations for each respondent. For 1,062 respondents this is the case. 486 respondents were observed three times and 496 twice.

\subsection{Measurements}

Institutionalization. At each observation, the respondent's address was examined to see whether he or she had moved in the preceding period. If respondents had moved, we asked in what type of housing they lived. Alternatives included a home-with-care or a nursing home. Interviewers also observed the housing type. Based on both measurements, a variable was constructed indicating whether or not the respondent had moved to an institution between two waves. If a respondent had died between waves, it was established whether he or she had been institutionalized before death. Short stays in a caring or nursing home were not registered as institutionalization. In our data, institutionalization is an absorbing state. Of the 265 transitions to either a home-with-care or a nursing home reported in our raw data, 29 were to a nursing home. Mainly because of this small share of immediate transitions to a nursing home, we did not distinguish between transitions to homes-with-care and nursing homes (in the strict sense of the word). We did not record whether 
respondents moved from a home-with-care to a nursing home. ${ }^{5}$ Because of the small number of transitions into a nursing home, we collapsed both transitions into one variable indicating institutionalization. This may imply that results concerning hypothesis $2 \mathrm{a}$ (the effect of the policy change) underestimate a true effect.

Care-at-home. Respondents were asked if they received help with personal care (yes or no). If they responded positively, they could indicate up to twelve sources of help, ranging from the partner, children and other informal carers to a variety of formal carers. Personal care is defined as having at least help with one of the following activities: to wash, to bath or shower, dressing and undressing, to go to the toilet, to get up and sit down. The same procedure was followed with respect to domestic tasks (no, yes), indicating activities like preparing meals, doing groceries, cleaning the house, taking the garbage bags outside, but also filling out forms. If any source of care-at-home was mentioned, we considered the respondent to receive care-at-home.

Housing tenure. In 1992, respondents were asked if they owned their house. Alternatives were own property, rented, sublet, free of charge. The first alternative (own property) was scored as home ownership. Outright owners have very low out-of-pocket user costs and could therefore be expected to stay as long as possible in their home. Owners were asked whether their house was free of mortgage. They could answer yes or no.

Health. To provide a sufficiently complete and concise overview of the respondent's (unobserved) health, we use five indicators which were assessed at each wave:

(a) Interviewers asked about the presence of seven chronic diseases: lung disease, cardiac disease, arteriosclerosis, stroke, diabetes, arthritis and malignant neoplasm. We counted the number of chronic conditions mentioned.

(b) Self reported functional ability is measured as the ability to perform six activities in daily life (ADL), e.g., "Can you walk up and down stairs?" The five possible answers were: not at all, only with help, with a great deal of difficulty, with some difficulty, and without difficulty. The six items constituted hierarchically homogeneous scales at the observations (Loevinger's $H \geq .59$ ), which were reliably measured $(\rho \geq .83$ ). The scale ranges from 0 (no disability) to 24 (severe disability).

\footnotetext{
${ }^{5}$ Since the time between subsequent waves is app. 3 years, it is possible that some of the 29 moves to nursing homes were in fact moves to a home-with-care followed by a move to a nursing home
} 
(c) Cognitive ability is measured with the 30-item Mini Mental State Examination (MMSE; Folstein et al., 1975). The scale ranges from 0 (minimum ability) to 30 (maximum ability) points. (d) Depressive symptoms are assessed with the Center for Epidemiologic Studies Depression Scale (CES-D), a 20-item scale (Radloff, 1977) which has been widely used in older populations. Scores range from 0 to 60 .

(e) Frailty is indicated by the respondent's gait speed, measured as the number of seconds needed to walk ten feet and back.

Availability of children. We included the total number of children and the number of living children within 30 minutes travel distance reported by the respondents. To compensate for skewness, we used a log transformation in some of the analyses.

Neighborhood involvement. Respondents were asked for the number of years a respondent has been living in the same neighborhood. There also was an extensive identification procedure for the personal network of respondents. This included asking for people in the neighborhood with whom the respondent had frequent and important contact. For each of the people mentioned, respondents could indicate the frequency of contact, ranging from never (1) to daily (8). We counted the number of neighbors identified in the network, and the number of neighbors with whom the respondent had at least a monthly contact.

Special adjustments in the house. Respondents could say if they had any of eighteen adjustments, ranging from extra banisters to an alarm system or a special lift in the house.

Satisfaction with housing was measured with a direct question. Households could indicate to be dissatisfied (1), not satisfied (2) or satisfied (3) with their current housing situation.

\section{Control variables.}

Socio-economic status. Institutionalization, housing tenure and health are associated with socioeconomic status. We use educational level and $\underline{\text { income }}$ as indicators. Educational status was measured in 1992, as the highest level of education obtained. The nine response categories ranged between no school finished at all and a university degree. To improve international comparability, the variable was recoded into years of education. Income was asked at each wave as the net monthly household income. For respondents living with a partner, the answer was multiplied by 0.7 to obtain an individual income. There were twelve categories ranging from a class mean of 1,125 Euro/month (in 1992) to 5,570 Euro/month. 
Homeownership and long-term care

Presence of partner. The partner is an important source of help, and the loss of a partner can trigger institutionalization. Given the health disparities among renters and homeowners, the former will be more often without a partner. At each observation, we assessed the presence of a partner in the household. We use the presence of a partner at each wave.

In 1992, sex and age were recorded.

Urbanization and region. Housing tenure may be associated with local and regional differences that also affect the demand and supply of long-term care. Urbanization may affect the demand, which presumably is lower in less urbanized areas. We use a national measure indicating the number of addresses per square meter. The scale ranges from $1(<500$ adresses) to $5(>2,500$ adresses). Furthermore, van Gameren (2005) has documented regional differences in the length of waiting lists for caring and nursing homes in the Netherlands. He concludes that such differences exist and can be substantial. In order to control for the impact of spatial factors, we have introduced dummies for the three regions in which respondents were sampled.

\subsection{Method}

We concentrate on the transition from living independently to becoming institutionalized and develop a duration model to analyze this phenomenon. Since our data are observations at discrete points in time we calculate the (conditional) probability that a transition takes place between wave $t$ and wave $t+1$ for $t=1 . .4{ }^{6}$ We use a logit to model the transition probability $p_{t}$ that a respondent who is in state 0 at the beginning in wave $t$ will be in state 1 in wave $t+1$. As explanatory variables for the transition probability of respondent $i$ we use his characteristics $X_{i t}$ at wave $t$. Note that information about the respondent in two subsequent waves is needed to determine whether a transition has taken place between $t$ and $t+1$.

The likelihood for each respondent $i$ who becomes institutionalized between wave $T$ and $T+1$ equals: $\Pi_{t=1}^{T-1}\left(1-p_{t}\left(X_{i t}\right)\right) p_{T}\left(X_{i t}\right)$. This respondent may have been observed in later waves than $T+1$ as well, but since he or she is then in a different state, information is not useful for estimating the transition probability in which we are interested here. If a respondent is observed between waves 1 and $T$ and is not institutionalized, the likelihood of this observation is $\prod_{t=1}^{T}(1-$ $\left.p_{t}\left(X_{i t}\right)\right)$. Note that $T$ may be smaller than 4 , for instance because the respondent died before wave 5. Although the large majority of the respondents is observed from $t=1$ until a later wave,

\footnotetext{
${ }^{6}$ This conditional probability is a discrete time hazard. See, for instance, Cameron and Trivedi (2005), pp 602-3.
} 
there are also cases in which a respondent is not observed at $t=1$, but only in later waves. In such cases the reason for the lacking observations is partial non response on some of the variables that are important for the purposes of the present paper in one or more waves. We have also included these observations in the estimations by appropriately adjusting the formulation of the likelihood. For instance, if we observe respondent $j$ only in waves 2,3 and 4 and she is institutionalized between waves 3 and 4 , the likelihood of this observation is $\left(1-p_{2}\left(X_{j 2}\right)\right) p_{3}\left(X_{i 3}\right)$.

A major advantage of this approach is that it allows us to introduce time varying covariates in a very easy way. This is especially important for health status, which is an important predictor of institutionalization. Changes in health care policy are also easy to deal with by incorporating time dummies. Individual effects can be introduced into the model through a random effects panel specification.

In a first round, we used a stepwise procedure to assess the effects of including each of the four confounding effects discussed in section 2 above on the impact of homeownership on the hazard of becoming institutionalized. The results of this exercise are reported in the next section. In section 6 we deal with the effects that were more closely related to ownership.

In section 7 we focus on the transition from living independently to either substantial care at home or institutionalization. There we use an extension of the model just discussed to three states: living independently without consuming substantial care at home, consuming substantial care at home, and being institutionalized. This extension is a simple competing risk model. The individual likelihoods used in this extended model are completely analogous to those formulated above. We use the same explanatory variables in this extended model.

\section{The robustness of the impact of homeownership on institutionalization}

\subsection{Descriptives}

Descriptive information on the variables included in the analysis is provided in Table 1. In spite of the increasing age of the sample, we do not see a linear increase in the rate of institutionalization. The percentage institutionalized hovers around $3 \%$ of the respective samples at each wave. The use of care at home decreases over time. This indicates selective attrition in the sample: the more frail respondents die earlier or are more often unable to complete the interview 
Homeownership and long-term care

Table 1 Description of variables in the model (means and percentages)

\begin{tabular}{|c|c|c|c|c|}
\hline & Wave 1 & Wave 2 & Wave 3 & Wave 4 \\
\hline & $1992 / 3$ & $1995 / 6$ & $1998 / 9$ & $2001 / 2002$ \\
\hline$N($ obs $)$ & 2238 & 2015 & 1566 & 1207 \\
\hline Homeowner (\%) & 42 & 42 & 44 & 46 \\
\hline Institutionalized $^{a}(\%)$ & 2.5 & 3.5 & 3.0 & 2.5 \\
\hline Use of care at home & $2.3 \%$ & $1.7 \%$ & $1.0 \%$ & $0.6 \%$ \\
\hline Year of birth & $1923(8.4)$ & $1924(8.3)$ & $1926(7.8)$ & $1927(7.1)$ \\
\hline Sex (\% women $)$ & 52 & 53 & 53 & 53 \\
\hline Education (\#years) & $9.0(3.3)$ & $9.1(3.4)$ & $9.2(3.3)$ & $9.4(3.3)$ \\
\hline Frailty & $8.0(3.6)$ & $.4(4.8)$ & $9.3(5.1)$ & $9.1(4.5)$ \\
\hline$A D L$ & $28.1(3.6)$ & $27.5(4.0)$ & $27.3(4.2)$ & $27.2(4.0)$ \\
\hline Depressive & $7.3(7.2)$ & $7.8(7.6)$ & $8.1(7.1)$ & $8.6(7.1)$ \\
\hline$M M S E$ & $27.4(2.3)$ & $27.2(2.7)$ & $27.4(2.4)$ & $27.4(2.5)$ \\
\hline Chronic illnesses & $0.8991 .0)$ & $1.13(1.1)$ & $1.28(1.1)$ & $1.30(1.0)$ \\
\hline Living with partner (\%) & 71 & 65 & 64 & 63 \\
\hline \# children & $3.0(2.1)$ & $3.0(2.1)$ & $2.9(2.0)$ & $2.9(1.9)$ \\
\hline \# Children within 30 min & $1.5(1.3)$ & $1.5(1.4)$ & $1.4(1.3)$ & $1.4(1.2)$ \\
\hline Urbanization & $2.9(1.5)$ & $3.0(1.5)$ & $3.1(1.4)$ & $3.0(1.4)$ \\
\hline Region & $2.2(1.1)$ & $2.2(1.1)$ & $2.2(1.1)$ & $2.0(1.3)$ \\
\hline $\begin{array}{c}\text { Years of residence in } \\
\text { neighborhood }\end{array}$ & $23(17)$ & $24(17)$ & $25(18)$ & $25(17)$ \\
\hline \# neighbors & $9.9(8.6)$ & $10.0(8.8)$ & $10.1(9.1)$ & $10.2(8.8)$ \\
\hline \# freq contacted nbrs & $6.0(5.6)$ & $5.8(5.4)$ & $5.8(5.5)$ & $5.9(5.5)$ \\
\hline \# adjustments & $0.18(.39)$ & $1.21(.41)$ & $1.30(.46)$ & $1.30(.46)$ \\
\hline Housing satisfaction & $2.88(.42)$ & $2.90(.36)$ & $2.91(.34)$ & $2.92(.34)$ \\
\hline
\end{tabular}

${ }^{\mathrm{a}}$ Institutionalized between this wave and the next. Standard deviations in parentheses. 
than the healthier ones.

The share of homeowners increases slightly over time. This is partly caused by the selection process just noted, but also by the larger propensity of renters to become institutionalized. A very small number of respondents have moved from privately owned to rental housing, but more moves in the opposite direction were reported. ${ }^{7}$

All health indicators, apart from the MMSE, point at slightly decreasing performance over time. The relatively small change in the average value of these variables is, of course, also related to selective attrition of those with the worst health condition either through death or being unable to fill out the questionnaire.

Table 2 provides the raw data on institutionalization and housing tenure in our sample. The figures in the table confirm that institutionalization occurs much less among homeowners than among renters. Among those transiting to an institution, the share of owner-occupiers is much lower. Clearly, homeowners differ substantially from renters in their propensity to become institutionalized. We will now consider first how much of this difference can be attributed to compositional differences between owners and renters.

Table 2 Moves to nursing and residential homes

\begin{tabular}{|l|r|r|r|r|}
\hline & \multicolumn{2}{|l|}{ Between waves: } \\
\hline & \multicolumn{1}{|l|}{ 1 and 2 } & 2 and 3 & 3 and 4 & \multicolumn{1}{|l|}{ and 5 } \\
\hline From renting & $51(3.9 \%)$ & $57(4.9 \%)$ & $36(4.1 \%)$ & $24(3.7 \%)$ \\
\hline From owning & $6(0.6 \%)$ & $14(1.7 \%)$ & $11(1.6 \%)$ & $6(1.1 \%)$ \\
\hline Total & $57(2.5 \%)$ & $71(3.5 \%)$ & $47(3.0 \%)$ & $30(2.5 \%)$ \\
\hline
\end{tabular}

The figures in brackets give the moves as percentages of the associated total numbers of observations.

\subsection{Estimation results}

Estimation results are presented in Table 3. Our most elementary specification is reported in column (1): we only use a constant and a homeownership dummy. The significant negative coefficient confirms the findings of Table 2. The second column reports our basic specification in which we use dummies for waves $\mathrm{t}=2,3$, and $4,{ }^{8}$ and the individual's year of birth, sex and

\footnotetext{
${ }^{7}$ Over the whole period of observation 82 owners moved to the rental sector and 24 renters became owners.

${ }^{8}$ The role of these dummies is comparable to that of a flexible baseline hazard in continuous duration models.
} 
education as explanatory variables. Incorporation of these time and cohort dummies implies that we cannot also include the respondent's age as an explanatory variable. ${ }^{9}$ The results of this second model suggest that the probability of becoming institutionalized increased over the years. The year of birth has a strongly significant negative effect, implying that younger cohorts have a much lower propensity to become institutionalized. Women have a substantially larger propensity of becoming institutionalized, while more education has the opposite effect. The coefficient for homeownership drops substantially, but remains significant.

We noted above that the absence of control variables causes potentially serious bias in the coefficient of the homeownership dummy. To see if and to what extent this is indeed the case, we introduce four sets of such control variables. We start with what are arguably the most important variables in this respect: the health status indicators. Estimation results in column (3) show that frailty (measured as low walking speed) is positively related to becoming institutionalized, while high scores (= better performance) on ADL and MMSE indicators are negatively correlated with institutionalization. Respondents reporting chronic illnesses and depressive symptoms do not become institutionalized more frequently. The coefficients for the time dummies are all much smaller and insignificant, which suggests that they mainly picked up the effects of deteriorating health in the previous specification. The coefficient for the year of birth also becomes smaller, but remains highly significant. Sex and education are no longer significant, which may be interpreted as saying that our health care indicators control effectively for health effects that are correlated with these two variables. The effect of homeownership on institutionalization is reduced to $50 \%$ of its value in the earlier model, but it remains negative and significant.

In the next variant of the model we introduce the presence of a partner in the household and the logarithm of (the number of children +1 ). ${ }^{10}$ Column 4 reports estimation results. Only the dummy indicating the presence of a partner has a significant coefficient. Again, the coefficient for homeownership decreases somewhat, but it remains significant with a (robust) $t$-ratio of 2.8. We have experimented with several other indicators for the effect of children (a dummy for having at least one child, the (untransformed) number of children, the number of children living within 30 minutes of travel time and the number of children living with the respondent). However, the estimated coefficients for these alternative variables were never significant.

\footnotetext{
${ }^{9}$ The reason is that there is a linear relationship between time, age and year of birth.

${ }^{10}$ This variable is equal to 0 when the number of children equals 0 , and increases less than proportionally with the number of children.
} 
Homeownership and long-term care

Table 3 Estimation results of a discrete time transition model for institutionalization

\begin{tabular}{|c|c|c|c|c|}
\hline & (1) & (2) & (3) & (4) \\
\hline Constant & $\mathbf{- 3 . 1 2}(.08)$ & $\mathbf{- 0 . 1 7}(.33)$ & $4.62(.83)$ & $\mathbf{4 . 3 2}(.88)$ \\
\hline Wave 2 & & $0.44(.19)$ & $0.16(.19)$ & $0.14(.19)$ \\
\hline Wave 3 & & $\mathbf{0 . 5 6}(.21)$ & $0.15(.22)$ & $0.13(.23)$ \\
\hline Wave 4 & & $\mathbf{0 . 7 2}(.24)$ & $0.24(.26)$ & $0.09(.28)$ \\
\hline Year of birth & & $\mathbf{- 0 . 1 7}(.01)$ & $\mathbf{- 0 . 1 2 ( . 0 1 )}$ & $\mathbf{- 0 . 1 1}(.01)$ \\
\hline Gender & & $0.35(0.16)$ & $0.18(.18)$ & $0.05(.19)$ \\
\hline Education & & $\mathbf{- 0 . 0 5 4}(.026)$ & $0.008(.03)$ & $0.02(.03)$ \\
\hline Homeowner $(y / n)$ & $-1.26(.18)$ & $\mathbf{- 0 . 6 4 ( . 1 9 )}$ & $\mathbf{- 0 . 6 1 ( . 2 0 )}$ & $\mathbf{- 0 . 5 9}(.23)$ \\
\hline & \multicolumn{4}{|c|}{ Health indicators } \\
\hline \# Chr. Illnesses & & & $-0.03(.07)$ & $-0.01(.07)$ \\
\hline$A D L(l o-h i)$ & & & $\mathbf{- 0 . 0 8 1}(.02)$ & $\mathbf{- 0 . 0 7 8}(.02)$ \\
\hline MMSE (lo-hi) & & & $\mathbf{- 0 . 1 5}(.02)$ & $\mathbf{- 0 . 1 5}(.02)$ \\
\hline Depressive (lo-hi) & & & $-0.00(.01)$ & $-0.00(.01)$ \\
\hline \multirow[t]{2}{*}{ Frailty } & & & $\mathbf{0 . 0 2 7}(.01)$ & $\mathbf{0 . 0 3 0}(.01)$ \\
\hline & \multicolumn{4}{|c|}{ Demographic indicators } \\
\hline Partner present & & & $\mathbf{- 0 . 4 3}(.20)$ & $\mathbf{- 0 . 4 1}(.20)$ \\
\hline \multirow[t]{2}{*}{$\log (\#$ children+1) } & & & $0.15(.13)$ & $0.11(.13)$ \\
\hline & \multicolumn{4}{|c|}{ Supply controls } \\
\hline Urbanisation & & & & Yes \\
\hline \multirow[t]{2}{*}{ Region } & & & & Yes \\
\hline & \multicolumn{4}{|c|}{ Social network indicators } \\
\hline Years in nbrhd & & & & $0.001(.004)$ \\
\hline$N($ resp $)$ & 2372 & 2372 & 2372 & 2372 \\
\hline$N(o b s)$ & 7026 & 7026 & 7026 & 7026 \\
\hline Loglikelihood & -756.7 & -706.5 & -703.6 & -695.5 \\
\hline
\end{tabular}

Robust standard errors in parentheses. The number of respondents refers to the number of persons that we observe in at least two subsequent waves and that provided enough information to include them in our model. The number of observations is the number of times respondents provided sufficient information in subsequent waves to include this information into our estimation model. See the Appendix. 
We control for availability of long term care by introducing dummies for the regions in which our respondents were living and for the degree of urbanization of their municipality of residence. Differences in supply due to differences in population density or regional capacity problems should be captured by these variables. However, none of the coefficients for the dummies that we introduce are significant. We introduce 8 dummy variables and the loglikelihood increases by approximately 8 points; the implied p-value is just over $5 \%$. The coefficient for the homeownership dummy hardly changes.

This remains the case of a variable indicating the social (neighborhood) capital of the respondent is introduced. In column (4) of Table we have taken the number of years a respondent has been living in his or her present neighborhood, but similar results (an insignificant coefficient for the social capital indicator) were reached when we included the number of neighbors or the number of neighbors with whom the respondent has frequent contacts.

In order to better take into account the panel nature of the data, all model specifications have been rerun with a random effects logit model. This resulted in very modest changes of the estimated coefficients. In particular, the coefficient for homeownership hardly changed and was significant in all model variants.

A final concern we addressed is that homeowners may first move to the rental sector when their health deteriorates, and subsequently become institutionalized. This could bias our results with respect to homeownership. We therefore constructed a new variable that indicated if a respondent has been observed as a homeowner in the previous or present wave and used this variable instead of the homeownership dummy that indicates homeownership in the present wave. The effect is this change is that renters who were previously observed as owners are now treated as if they still were owners. The results of the modified model were similar to those of the original one. In the most extensive model (column 4) the homeownership coefficient increases in absolute value to -0.68 (the standard error remains .23). We conclude that our results are not biased by selective movement to the rental sector of homeowners in bad health.

Summarizing, we have to conclude that after controlling for four potentially important compositional effects, we still find a statistically significant negative effect of homeownership on the institutionalization hazard. The effect is also significant from an economic point of view. The average institutionalization probability is 0.0292 , and the marginal effect of homeownership on the probability of becoming institutionalized is -0.0057 , implying a decrease of $20 \%$. It appears 
therefore that homeownership, or some mechanism closely related to it, is responsible for a substantial part of the correlation between housing tenure and institutionalization. The next section provides a closer examination of three possibilities.

\section{Prices, bequests and quality differences}

\subsection{Homeownership and the cost of care}

The policy change in 1997 implies a major decrease of the cost of care in sheltered housing for people owning a non negligible amount of wealth. This group includes virtually all homeowners since very few elderly people have large amounts of mortgage debt. Given the size of the change, one can easily imagine a measurable effect on the institutionalization rates. There exists some casual evidence about families who took care of their parents until their health was deteriorated so much that immediate admission to a nursing home had become necessary, while most people who cannot receive the required care at home first move to sheltered housing.

We documented in section 4 that only a small fraction of the respondents in our data who became institutionalized (reported to have) moved to a nursing home immediately and it makes no sense to analyze this group separately. ${ }^{11} \mathrm{We}$ would expect that homeowners made the transition to institutionalized care (either in a nursing home or sheltered housing) less often than renters in otherwise comparable circumstances due to the much higher price they had to pay. Since the policy change took place in 1997, we expect especially that this had an impact on the hazard of becoming institutionalized between the first and second wave (in 1992/3 and 1995/6, respectively). To test for the presence of this effect, we included a dummy that indicates the cross effect of being a homeowner and the dummy indicating wave 1. We use the model of column (3) in Table 3 as our reference.

Estimation results for the homeownership dummy and the cross effect of the extended model are reported in Table 4. The column indicated by (3) in that table repeats some results of the analogous column in Table 3. Column (4) refers to the extension just discussed. The coefficient estimated for the cross-effect has the expected negative sign. It is significant at the $10 \%$ level, but not at the $5 \%$ level. The coefficient for the homeownership dummy is now

\footnotetext{
${ }^{11}$ Less than $50 \%$ of the institutionalized respondents indicate whether they are in sheltered housing or in a nursing home. Of those who provide this information 14\% indicates (a total of 30 observations, including those who are in a nursing home in more than ones wave) to be in a nursing home.
} 
Homeownership and long-term care

insignificant, even at the $10 \%$ level. This result may be interpreted as weak evidence in favor of the hypothesis that homeowners were more reluctant than renters to enter institutionalized care before 1997.

Table 4 Impacts of the policy change in 1997

\begin{tabular}{|l|c|r|r|r|r|}
\hline & $(3)$ & $(4)$ & \multicolumn{1}{c|}{$(5)$} & \multicolumn{1}{c|}{$(6)$} & \multicolumn{1}{c|}{$(7)$} \\
\hline Homeowner & $\mathbf{- 0 . 6 1}(.20)$ & $-0.37(.23)$ & $-0.29(.30)$ & $\mathbf{- 0 . 8 5}(.42)$ & $\mathbf{- 0 . 8 4}(.26)$ \\
\hline Homeowner*(w1) & & $-0.87(.48)$ & & & \\
\hline Outright owner & & & & $0.53(.48)$ & $0.71(.51)$ \\
\hline Outright owner*(w1) & & & & $-0.84(.52)$ & \\
\hline Homeowner*(w1+w2) & & & $-0.49(.40)$ & & \\
\hline Outright owner*(w1+w2) & & & & & $-0.66(.43)$ \\
\hline & & & & & \\
\hline & 7026 & 7026 & 7026 & 7021 & \\
\hline Loglikelihood & -703.60 & -701.60 & -702.50 & -701.44 & -701.90 \\
\hline
\end{tabular}

To further explore this issue, we estimated a variant of the model in which the cross effect of being a homeowner and waves 1 and 2 was included as an additional variable. The idea behind this specification is that also between the second and third waves institutionalization of homeowners was less likely to be observed as the policy change was only effective in the last part of this period. However, estimation results, reported in column (5), do not confirm this conjecture. The coefficient for the cross effect and the coefficient for the homeownership dummy are now both insignificant at the $10 \%$ level.

Since one may conjecture that especially homeowners with a large amount of home equity would be sensitive to the higher cost of long term care, we formulated a third model in which the interaction between outright ownership (having no mortgage loan) and wave 1 is included. The results of estimating this model, in which also a dummy for outright homeownership was included, are reported in column (6). The coefficient for the cross effect is insignificant (the p-value is .107) but the homeownership dummy is now significant. Extending the cross effect to wave 2 does not improve the model. 
Homeownership and long-term care

We must therefore conclude that we can find only very weak evidence that the higher cost of care in sheltered housing caused the lower transition rates to institutionalized care of homeowners. We have also checked these results by using a random effects panel data specification for the logit model, and found only marginal changes in the estimation results.

Table 5 Impacts of children

\begin{tabular}{|l|r|r|r|r|r|}
\hline & $(3)$ & \multicolumn{1}{c|}{$(8)$} & \multicolumn{1}{c|}{$(9)$} & \multicolumn{1}{c|}{$(10)$} & \multicolumn{1}{c|}{$(11)$} \\
\hline Homeowner & $\mathbf{- 0 . 6 1}(.20)$ & $\mathbf{- 1 . 4 8}(.64)$ & $\mathbf{- 1 . 0 4}(.46)$ & $\mathbf{- 0 . 5 7}(.28)$ & $\mathbf{- 0 . 6 3}(.21)$ \\
\hline Ch1 & & $-0.03(.27)$ & & & \\
\hline Ch2 & $0.15(.13)$ & & $0.08(.14)$ & & \\
\hline Ch3 & & & & $0.11(.58)$ & \\
\hline Ch4 & & & & & $-0.61(.63)$ \\
\hline Homeowner*ch1 & & $1.03(.67)$ & & & \\
\hline Homeowner*ch3 ${ }^{*}$ ch2 & & & $0.37(.32)$ & & \\
\hline Homeowner*ch4 & & & & $-0.02(.13)$ & \\
\hline & & & & & $1.04(.87)$ \\
\hline & 7026 & 7026 & 7026 & 7021 & \\
\hline Loglikelihood & -703.6 & -702.5 & -702.5 & -702.1 & -703.2 \\
\hline
\end{tabular}

Legend: $\operatorname{ch} 1=$ at least one child, $\operatorname{ch} 2=\log ($ number of children +1$), \operatorname{ch} 3=\log ($ number of children at travel distance $<30$ $\mathrm{min}), \mathrm{ch} 4=$ at least one child living with respondent

\subsection{A strategic bequest motive?}

Our data permit us to investigate a strategic bequest motive by extending the model of the previous section with cross effects of homeownership and variables related to the presence of children. We used four indicators of the possible effect of children: an indicator for the respondent having at least one child (ch1), the logarithm of the number of children plus one (ch2), the number of children living at less then $30 \mathrm{~min}$. travel time (ch3) and an indicator for at least one child living with the respondent (ch4). We used the model of column (3) of Table 3 again as our reference. The variants we considered have one of the four variables just discussed and their product with the homeownership dummy as explanatory variables. Estimations results are presented in Table 5. 
Homeownership and long-term care

The cross effects are never significant and have the wrong sign in three out of four cases. When the number of children living close to the respondent is used, the cross effect has the expected sign, and the coefficient of the uncrossed indicator is almost significant at the 5\% level. It is clear therefore that the strategic bequest motive finds no support in our data. If anything, the data suggest that children have a positive effect on the propensity to move to a nursing home.

\subsection{More suitable houses?}

Our last set of hypotheses concerns the greater investment of owners in the quality of their homes and in special adjustments that enable continuing to live independently. Table 6 summarizes relevant characteristics. The first panel of this table shows that homeowners live in a detached house far more often than renters. These detached houses are often 'empty nests' with plenty of room and a garden which presumably become more of a burden to live in when health deteriorates. Nevertheless, $30 \%$ of the homeowners lived in such houses in all four waves.

The second panel refers to houses that are especially designed for elderly people, and shows that only $2 \%$ of the owners live in such housing, while $10-15 \%$ of the renters do so. The third panel shows the percentage of respondents that moved to a house that has all rooms on the same floor. (This information was not available for the whole sample.) Less than $50 \%$ of those moving to an owner occupied house do so, which contrasts sharply with the more than $75 \%$ of the respondents who moved to a rental house with this characteristic. Finally, we see that 10-20\% of the owners have special adjustments in their house, whereas $20-40 \%$ of the renters have this type of facilities. For both groups the share of households living in a house with special adjustments increase over time, which suggests that these adjustments are made in response to health problems.

To further investigate the possible effect of housing type on institutionalization we have included dummies for detached housing and elderly housing in the most elaborate version of our basic model (see column 4 of Table 3). Both coefficients had the expected sign (positive for detached housing and negative for elderly housing) but were very far from significant. These findings are possibly biased by endogeneity of housing type choice (when health deteriorates, one may move to elderly housing to avoid institutionalization). However, both intuition and our data point to the fact that owners are overrepresented in housing types that make institutionalization somewhat more likely, rather than less. For this reason it seems highly improbable that we can 
Homeownership and long-term care

explain the lower propensity of homeowners to become institutionalized by elaborating on the choice of the housing type.

Table 6 Some characteristics of owner-occupied and rental housing

\begin{tabular}{|c|c|c|c|c|c|}
\hline \multirow[t]{2}{*}{ Characteristic } & \multirow{2}{*}{$\begin{array}{l}\text { Housing } \\
\text { tenure }\end{array}$} & \multicolumn{4}{|l|}{ Wave } \\
\hline & & 1 & 2 & 3 & 4 \\
\hline \multicolumn{6}{|l|}{ Detached } \\
\hline & Owners & 29 & 31 & 30 & 30 \\
\hline & Renters & 3 & 2 & 2 & 2 \\
\hline \multicolumn{6}{|l|}{ Elderly housing } \\
\hline & Owners & 2 & 2 & 2 & 2 \\
\hline & Renters & 11 & 14 & 15 & 13 \\
\hline \multicolumn{6}{|c|}{ House with all rooms on the same floor (recent movers only) } \\
\hline & Owners & 41 & 40 & 56 & 35 \\
\hline & Renters & 77 & 77 & 76 & 86 \\
\hline \multicolumn{6}{|c|}{ Special adjustments } \\
\hline & Owners & 12 & 14 & 21 & 20 \\
\hline & Renters & 22 & 27 & 36 & 38 \\
\hline
\end{tabular}

Legend: the figures give the percentages of the respondents in the specific type of housing conditional on tenure type.

To get some insight into the determinants of the presence of special adjustments in the house, we estimated a linear probability panel data model. Table 7 reports results from a random and fixed effects specification. The random effects specification shows that homeowners live less often in a house with special adjustments after controlling for health and socio-economic variables. The fixed effects specification provides interesting additional evidence because the significant negative coefficient for homeownership shows that moving from owning to renting implies a larger probability of moving towards a house with special adjustments than moving in the opposite direction. This suggests that the need for special adjustments in the house induces some owners to move to the rental sector. Alternatively, it could be the case that elderly that 
Homeownership and long-term care

move to the rental sector for reasons unrelated to health (for instance, the desire to consume their home equity, as suggested by Artle and Varaiya (1978)), often choose a house that is suitable for the needs of old age because of the presence of special adjustments. Since the number of moves from the owner-occupied sector to the rental sector is very small, we did not investigate this issue further.

Table 7 Special adjustments

\begin{tabular}{|l|r|r|}
\hline & Random effects & \multicolumn{1}{l|}{ Fixed effects } \\
\hline Constant & $\mathbf{0 . 8 0}(.08)$ & $\mathbf{0 . 6 9}(.13)$ \\
\hline Wave 2 & $\mathbf{0 . 0 2}(.01)$ & $\mathbf{0 . 0 3}(.01)$ \\
\hline Wave 3 & $\mathbf{0 . 1 0}(.01)$ & $\mathbf{0 . 1 0}(.01)$ \\
\hline Wave 4 & $\mathbf{0 . 1 2}(.01)$ & $\mathbf{0 . 1 2}(.02)$ \\
\hline Year of birth & $\mathbf{- 0 . 0 0 7}(.001)$ & - \\
\hline & & \\
\hline Homeowner & $\mathbf{- 0 . 8 5}(.01)$ & $\mathbf{- 0 . 1 7}(.04)$ \\
(n/y) & & \\
\hline & & \\
\hline Walk & $\mathbf{0 . 0 0 3 8}(.001)$ & $\mathbf{0 . 0 0 4 0}(.002)$ \\
\hline ADL (lo-hi) & $\mathbf{- 0 . 0 2 0 0}(.001)$ & $\mathbf{- 0 . 0 1 3 8}(.003)$ \\
\hline Depressive (lo- & $-0.0014(.001)$ & $-0.0019(.003)$ \\
hi) & & \\
\hline MMSE (lo-hi) & $-0.0022(.002)$ & $-0.0032(.003)$ \\
\hline \# Chr. Illnesses & $0.0052(.006)$ & $0.0039(.010)$ \\
\hline & & $-0.03(.03)$ \\
\hline Gender & $\mathbf{0 . 0 3}(.01)$ & - \\
\hline Education & $-0.00(.00)$ & \\
\hline Partner present & $-0.02(.01)$ & - \\
\hline Log (\# children) & $\mathbf{0 . 0 3}(.01)$ & \\
\hline$N$ & & \\
\hline
\end{tabular}

A final hypothesis to be considered in this section is that homeowners are more attached to their current housing situation than renters and for this reason are more reluctant to move. In our data the elderly homeowners are less mobile on the housing market than renters, as has been observed 
Homeownership and long-term care

earlier in the literature. However, we have already seen that the years spent in the present neighborhood, which is closely related to the duration of stay in the present house, does not affect the propensity to move to institutionalized care.

Table 8 Satisfaction with current housing situation

\begin{tabular}{|l|r|r|}
\hline & \multicolumn{1}{|l|}{ Random effects } & \multicolumn{1}{l|}{ Fixed effects } \\
\hline Constant & $\mathbf{2 . 9 6}(.09)$ & $\mathbf{2 . 9 9}(.13)$ \\
\hline Wave 2 & $\mathbf{0 . 0 3}(.01)$ & $\mathbf{0 . 0 3}(.01)$ \\
\hline Wave 3 & $\mathbf{0 . 0 5}(.01)$ & $\mathbf{0 . 0 4}(.01)$ \\
\hline Wave 4 & $\mathbf{0 . 0 6}(.01)$ & $\mathbf{0 . 0 4}(.02)$ \\
\hline Year of birth & $\mathbf{- 0 . 0 0 2}(.001)$ & \\
\hline & & \\
\hline Homeowner (n/y) & $\mathbf{0 . 0 9 1}(.01)$ & $0.05(.04)$ \\
\hline & & \\
\hline Walk & $-0.0014(.001)$ & $0.0018(.002)$ \\
\hline ADL (lo-hi) & $-0.0005(.001)$ & $-0.0017(.003)$ \\
\hline Depressive (lo-hi) & $\mathbf{- 0 . 0 0 7 4}(.001)$ & $\mathbf{- 0 . 0 0 3 9}(.001)$ \\
\hline MMSE (lo-hi) & $-0.0003(.002)$ & $-0.0019(.004)$ \\
\hline \# Chr. Illnesses & $0.0033(.005)$ & $0.0026(.011)$ \\
\hline & & \\
\hline Gender & & \\
\hline Education & $-0.00(.00)$ & \\
\hline Partner present & $-0.01(.01)$ & $0.03(.03)$ \\
\hline Log (\# children) & $0.01(.01)$ & - \\
\hline & & \\
\hline N & & \\
\hline & & \\
\hline
\end{tabular}

Our respondents also report their satisfaction with the current housing situation, which presumably reflects attachment to the current house at least as well as the duration of stay. However, a possible concern with this variable is that it may be highly endogenous in the sense that deteriorating health and the need to receive substantial care almost automatically leads to 
decreased satisfaction with one's current housing situation. To investigate this issue, we carried out a simple panel data regression on expressed housing satisfaction. Housing satisfaction is measured in three classes, and a large majority of the respondents indicates being very satisfied with their present housing situation. Although the variation in the dependent variable is therefore limited, we undertook a panel data analysis.

Results are reported in Table 8. In the random effects regression the coefficient on the homeownership dummy is positive and strongly significant. Owners are significantly more satisfied with their current housing situation than renters, as we expected. The coefficient of the fixed effect regression, whose value is determined by moves between the two sectors, is also positive, but insignificant. Those who move from the owner-occupied to the rental sector do not express higher satisfaction with their housing situation afterwards. Depressive symptoms are the only health variable that significantly affects housing satisfaction. Difficulties with walking or a low ADL score, which may make it more difficult to continue living in large houses are not reflected in lower expressed satisfaction with one's current housing situation.

The most important aspect of these results is that health does hardly affect expressed satisfaction with one's house. This makes it more likely that this variable is a good indicator of one's attachment to the current housing situation. To see if expressed housing satisfaction can help explain the lower propensity to become institutionalized of homeowners, we have included this variable into the most extensive version of the basic model (see column 4 of Table 3). Although we found a coefficient with the expected negative sign, it was far from significant.

\section{Care-at-home}

Our results so far indicate that homeowners have a lower institutionalization hazard than renters, conditioning on a number of health indicators. Financial motivations play a modest role in this process, and we found no indication that the subjective and objective quality of the home is relevant. An implication of this finding is that homeowners can avoid institutionalization when their health condition is so bad that most renters would become institutionalized. It seems probable that they are able to do so by using some types of care-at-home. This is investigated in the present section.

We now distinguish three states instead of two: independent living without substantial care-at-home (0), being institutionalize (1) and independent living with a substantial amount of 
Homeownership and long-term care

care (2). We reformulate the duration model by specifying the hazards of a transition from state 0 to either state 1 or 2 as a multinomial logit model. 'Failure' is now defined as either institutionalization or receiving more than 40 hours care-at-home. The 40 hours per month threshold is used because it is clear that not all care-at-home can reasonably be regarded as a substitute for institutionalization. Care-at-home may be provided by professional caregivers, but also by the partner, by children or by other relatives.

Table 9 Transitions to institutionalization and substantial care-at-home

\begin{tabular}{|c|c|c|c|c|c|}
\hline \multirow[t]{2}{*}{ From } & \multirow[t]{2}{*}{ To } & \multicolumn{4}{|c|}{ Between waves: } \\
\hline & & 1 and 2 & 2 and 3 & 3 and 4 & 4 and 5 \\
\hline \multirow[t]{2}{*}{ Renting } & Inst & $51(4.0 \%)$ & $57(4.9 \%)$ & $35(4.1 \%)$ & $22(3.5 \%)$ \\
\hline & Care-at-home & $15(1.2 \%)$ & $14(1.2 \%)$ & $8(0.9 \%)$ & $5(0.8 \%)$ \\
\hline \multirow[t]{2}{*}{ Owning } & Inst & $6(0.7 \%)$ & $14(1.8 \%)$ & $11(1.7 \%)$ & $4(0.8 \%)$ \\
\hline & Care-at-home & $34(3.2 \%)$ & $20(2.5 \%)$ & $7(1.1 \%)$ & $2(0.4 \%)$ \\
\hline \multirow[t]{2}{*}{ Total } & Inst & $57(2.6 \%)$ & $71(3.6 \%)$ & $46(3.1 \%)$ & $26(2.2 \%)$ \\
\hline & Care-at-home & $49(2.3 \%)$ & $34(1.7 \%)$ & $15(1.0 \%)$ & $7(0.6 \%)$ \\
\hline
\end{tabular}

The numbers of transitions to states (1) and (2) is given in Table 9. For renters the transition rates to institutionalization are consistently higher than to substantial care-at-home, whereas for owners we see the reverse pattern. This suggests strongly that some owners use careat-home in situation in which renters become institutionalized. Another remarkable aspect of the figures presented in Table 9 is that the total number of transitions to institutionalized care is almost as large as in Table 2. This implies that only in a few cases we observe respondents who consume a substantial amount of care in one wave and are institutionalized in a later wave. In most cases respondents either take care-at-home (and do not become institutionalized) or become institutionalized. In part this is due to the nature of our data: when we observe that a respondent is institutionalized in a particular wave $t$, it is probable that he or she received a substantial amount of care-at-home during the period of waiting until a place in a caring or nursing home became available, but we do not observe this when this episode started after wave $t$ - 1 . However, care-athome during such a transitory stage is of limited interest for the purposes of the present analysis. Much more interesting are the cases in which respondents avoid becoming institutionalized by receiving care-at-home or to postpone it for a number of years rather than a few months while 
Homeownership and long-term care

waiting for institutionalization, and this seems to happen in quite a few cases, especially among homeowners, as we expected.

Table 10 Estimation results of a discrete time transition model for institutionalization and care-at-home

\begin{tabular}{|c|c|c|c|c|}
\hline & \multicolumn{2}{|c|}{ Model 1 (all care-at-home) } & \multicolumn{2}{|c|}{$\begin{array}{l}\text { Model } 2 \text { (care-at-home includes } \\
\text { professional care) }\end{array}$} \\
\hline & Institutionalization & Care-at-home & Institutionalization & Care-at-home \\
\hline Constant & $5.95(.89)$ & $2.17(1.7)$ & $4.23(.86)$ & $-0.31(3.3)$ \\
\hline Wave 2 & $0.14(.19)$ & $-0.29(.24)$ & $0.13(.19)$ & $0.66(.60)$ \\
\hline Wave 3 & $0.04(.23)$ & $\mathbf{- 0 . 8 9}(.32)$ & $0.09(.22)$ & $0.40(.68)$ \\
\hline Wave 4 & $-0.06(.29)$ & $\mathbf{- 1 . 3 9}(.24)$ & $-0.11(.27)$ & $0.84(.75)$ \\
\hline Year of birth & $\mathbf{- 0 . 1 1}(.01)$ & $-0.02(.02)$ & $\mathbf{- 0 . 1 1}(.01)$ & $-0.14(.04)$ \\
\hline Homeowner (n/y) & $\mathbf{- 0 . 5 4}(.21)$ & $\mathbf{0 . 6 9}(.23)$ & $\mathbf{- 0 . 5 3}(.20)$ & $0.44(.47)$ \\
\hline Walk & $\mathbf{0 . 0 4}(.01)$ & $\mathbf{0 . 0 4}(.02)$ & $\mathbf{0 . 0 4}(.01)$ & $0.02(.03)$ \\
\hline ADL (lo-hi) & $\mathbf{- 0 . 0 8}(.02)$ & $\mathbf{- 0 . 1 0}(.03)$ & $\mathbf{- 0 . 0 8}(.02)$ & $\mathbf{- 0 . 1 3}(.06)$ \\
\hline Depressive (lo-hi) & $-0.01(.01)$ & $\mathbf{- 0 . 0 4}(.02)$ & $-0.00(.01)$ & $-0.07(.04)$ \\
\hline MMSE (lo-hi) & $\mathbf{- 0 . 1 6}(.02)$ & $-0.02(.04)$ & $\mathbf{- 0 . 1 5}(.02)$ & $-0.04(.08)$ \\
\hline \# Chr. Illnesses & $0.02(.07)$ & $0.06(.10)$ & $0.03(.07)$ & $0.25(.17)$ \\
\hline Gender & $-0.01(.20)$ & $\mathbf{- 1 . 5 3 ( . 2 7 )}$ & $-0.01(.20)$ & $\mathbf{- 0 . 4 5}(.47)$ \\
\hline Education & $0.01(.03)$ & $0.06(.03)$ & $0.02(.03)$ & $0.01(.08)$ \\
\hline Partner present & $\mathbf{- 0 . 4 1 ( . 2 0 )}$ & $\mathbf{1 . 1 8}(.37)$ & $\mathbf{- 0 . 4 5}(.20)$ & $1.34(.58)$ \\
\hline Log (\# children+1) & $0.21(.13)$ & $\mathbf{0 . 5 3}(.23)$ & $0.18(.13)$ & $\mathbf{0 . 3 0}(.43)$ \\
\hline$N$ & 6767 & & 7009 & \\
\hline Loglikelihood & -1136. & & -819.3 & \\
\hline
\end{tabular}

(Robust standard errors in parentheses)

Estimation results of this extended duration model are presented in Table 9, in the columns indicated as model 1 . The specification is similar to that of column (4) in the univariate model of Table 3. The most important result is that, after controlling for a number of other 
variables, homeowners appear to substitute care-at-home for institutionalization as is indicated by the significant positive coefficient for homeownership in the care-at-home column. The estimated coefficients for the transition to institutionalized care are of the same order of magnitude as in that univariate model, as we expected on the basis of the information provided in Table 10.

The coefficients referring to health indicators are similar for both types of care except MMSE, which we interpret as confirming our belief that both types of care are substitutes in many situations. It seems plausible that care-at-home is not a good substitute for institutionalized care when someone's cognitive abilities are seriously deteriorated. The coefficients of the socioeconomic variables are much different for the two types of care. Clearly gender differences, and the presence of a partner and children affect the need for care by other persons. Another interesting aspect of the model is the downward trend in the coefficients for the time dummies, which probably reflects the diminishing generosity of the public health system in providing long term care.

One possible concern with this extended model is that care-at-home can mean a lot of different things, and many of them cannot be properly regarded as substitutes for the types of care provided in caring or nursing homes. For this reasons it seems worthwhile to see if the results just discussed are robust against a more restrictive definition of care-at-home. It seems especially relevant to require that some of the care received at home should be provided by professional care givers.

Estimation results for an alternative model in which this requirement is imposed are presented in the columns indicated as model 2 in Table 9. There are now more observations, because we have a more restrictive criterion for substantial care-at-home. However, there are few respondents that move to the more strictly defined state of care-at-home: over the whole period of observation their total number is 23,13 of them being renters. The coefficient of the dummy for homeownership in the care-at-home alternative is now insignificant, indicating that homeowners do not consume more of this type of care than renters, controlling for health and socio-economic variables. Note, however, that the standard errors of the estimated coefficients in the care-athome alternative are much larger in model 2 than they were in model 1 . This makes it hard to draw firm conclusions from model 2.

As an alternative sensitivity check, model 1 has been re-estimated with other threshold levels for the monthly hours of care-at-home (80 and 120 hours per month). The idea behind 
these specifications is that care-at-home can only be regarded as a substitute for care offered in an institutional setting when it is a substantial amount of care. In both alternative models a negative and significant coefficient for institutionalization of the same order of magnitude, and a positive coefficient for care-at-home of a smaller magnitude. If the 80 hours threshold is used the coefficient for homeownership in the care-at-home alternative is significant at the $10 \%$ level, but not at the 5\% level, if the 120 hours per month threshold is used it is significant at both levels.

\section{Conclusion}

By taking into account a wide array of possible explanations, this study has enabled us to develop and test a large number of hypotheses about the mechanism behind the differences in institutionalization between renters and owners. The LASA study is not only unique in its breadth, but also offers a panel spanning over fifteen years, allowing the incorporation of historic change. Some limitations need mentioning nevertheless. Foremost, sample attrition is a problem in collecting these data. Although great care has been taken in the data collection to include information from the more frail respondents through proxy interviews and post mortem information, we disproportionally lack data from respondents who are at high risk of becoming institutionalized. A second limitation is that we did not dispose of detailed information on the wealth of the respondents. The value of their home equity, and the value of other assets may shed more light on specific cost motives. It seems unlikely, however, that the robust relationship between homeownership and institutionalization we repeatedly found is caused by these data limitations.

The conclusion that remains is that elderly homeowners succeed in realizing lower transition rates to institutionalized care after all the possible explanatory factors considered in the present paper have been taken into account. Even if living in a large house limits access to careat-home and makes adaptations more costly (as is indicated by Easterlow and Smith, 2004), most elderly homeowners appear to just want to continue living in the current house which is relatively often a detached house, and they appear to be able to do so.

Our interpretation of these findings is that most elderly owner-occupiers actively try to stay in their house as long as possible. That is, they do not want to move to any other dwelling or nursing or residential home. A probable reason is that the cost of moving house - and especially its non-monetary part, the effort involved in realizing the move and becoming settled in a new 
environment - increases substantially with age and with decreasing health. In other words, the costs of moving rise at the same time when its potential benefits go up. The success of homeowners in delaying institutionalization increasingly becomes a obstacle against institutionalization in itself. There is a strong preference among the elderly for aging in place even if objective measures indicate that this place is becoming less suitable for them. It is then perhaps no surprise that this effect is much stronger for homeowners who have to leave behind their own property when becoming institutionalized, often for the remainder of their life. Moreover, homeowners appear to be more persistent in trying to realize their desire to stay in the house in which they often lived for a very long time than renters. Being the owner, they probably have a larger say in the decision to stay where they are than renters have in otherwise comparable circumstances. Moreover, as owners they have learned to be more self-reliant in housing issues than renters.

If this interpretation is correct, there are good reasons to facilitate the apparently strong preference for aging in place among elderly homeowners. This may not only be in their own best interest, but it will probably also have a mitigating effect on the demand for long term care which is expected to increase substantially in the coming decades. Following this suggestion could mean that more possibilities are offered for receiving long term care-at-home. This does not necessarily imply that more public money has to be spent: the often considerable amount of home equity accumulated by the elderly can probably be used to help finance such arrangements. The present-day (and future) elderly differ from earlier generations in pension and other wealth, in expected remaining life time, and also in their demand for care. It seems probable that the demand (willingness to pay) for personalized care arrangements will increase and that creative arrangements to use the home equity to make it effective are in principle attractive for all parties involved. 
Homeownership and long-term care

\section{References}

Artle R, Varaiya P. Life cycle consumption and homeownership. Journal of Economic Theory $1978 ; 18 ; 38-58$.

Banks J, Blundell RW, Oldfield Z, Smith JP. Housing price volatility and downsizing in later Life NBER working paper 13496, 2007.

Bernheim BD, Shleifer A, Summers LH. The Strategic Bequest Motive. Journal of Political Economy 1985; 93; 1045-1076.

Breeze E, Slogget A, Fletcher A. Socioeconomic and Demographic Predictors of Mortality and Institutional Residence among Middle Aged and Older People: Results from the Longitudinal Study. Journal of Epidemiology and Community Health 1999; 53; 765-774.

Broese van Groenou MI, Penninx BWJH, Deeg DJH. Socio-economic inequalities in health decline and mortality in an older population. Aging 2003; 15; 174-183.

Cameron, A.C. and P.K. Trivedi. Microeconometrics, Cambridge; 2005.

Compton J, Pollak RA. Proximity and coresidence of adult children and their parents: description and correlates. Michigan retirement research center working paper 2009-215; 2009.

Deeg DJH, van Tilburg T, Smit JH, de Leeuw ED. Attrition in the Longitudinal Aging Study Amsterdam: The effect of differential inclusion in side studies. Journal of Clinical Epidemiology 2002; 55; 319-328

Dietz RD, Haurin DR. The social and private micro-level consequences of homeownership. Journal of Urban Economics 2003; 54; 401-450.

Easterlow D, Smith SJ. Housing for health: can the market care? Environment and Planning 2004; 36; 999 $-1017$.

Folstein MF, Folstein SE, McHugh PR. "Mini-Mental State ": a practical method for grading the cognitive state of patients for the clinician. Journal of Psychiatric Research 1975; 12; 189-198

Fried LP, Tangen CM, Walston J, Newman AB, Hirsch C, Gottdiener J et al. Frailty in older adults: evidence for a phenotype. Journals of Gerontology 2001; 56A; M146-M156.

Gameren E van . Regionale verschillen in de wachtlijsten verpleging en verzorging (Regional differences in waiting lists for nursing and residential homes, in Dutch). Sociaal-Cultureel Planbureau; The Hague; 2005

Gaugler JE, Duval S, Anderson KA, Kane RL. Predicting nursing home admission in the U.S: a metaanalysis. BMC Geriatrics 2007; 7; 13

Geerlings SW, Pot AM, Twisk JWR, Deeg DJH. Predicting transitions in the use of informal and professional care by older adults. Ageing and Society 2001; 25;111-130.

Hank K. Proximity and Contacts Between Older Parents and Their Children: A European Comparison. Journal of Marriage and Family 2007; 69; 157-173.

Huisman M, Kunst AE, Bopp M, Borgan BK, Borrell C, Costa G, Deboosere P, Gadeyne S, Glickman M, Marinacci C, Minder C, Regidor E, Valkonen T, Mackenbach JP. Educational inequalities in cause-specific mortality in middle-aged and older men and women in eight western European populations. Lancet 2005; 365; 493-500.

Knipscheer CPM, de Jong Gierveld J, van Tilburg TG, Dykstra PA (Eds.) . Living arrangements and social networks of older adults. VU University Press: Amsterdam; 1995.

Muramatsu N, Yin H, Campbell RT, Hoyem RH, Jacob Ma, Ross CO. Risk of nursing home admission among older Americans: does state's spending on home- and community-based services matter? Journal of Gerontology 2007; 62B; S169-178.

Nihtilä E, Martikainen P. Household income and other socio-economic determinants of long-term institutional care among older adults in Finland. Population Studies 2007; 61; 299-314.

Norton EC 2000. Long term care. In: Culyer AJ, Newhouse JP (Eds), Handbook of Health Economics I, chapter 17, North Holland, p. 955-994. 
Homeownership and long-term care

Radloff LS. The CES-D scale: A self-report depression scale for research in the general population. Applied Psychological Measurements 1977; 3; 385-401

Redfoot DL. 'On the separatin' Place'. Social class and relocation among older women. Social Forces 1987; 66; 486-500.

Rohe WM, Stewart LS. Homeownership and neighbourhood stability. Housing Policy Debate 1996; 7; 37 81.

Rouwendal J. Housing wealth and household portfolios in an ageing society. De Economist 2009; 157; 148.

Sampson RJ, Morenoff JD, Earls F. Beyond social capital: spatial dynamics of collective efficacy for children. American Sociological Review 1999; 64; 633-660.

Staatscourant. Bijdragebesluit zorg, Staatsblad 486; 1996.

Thomese F, Broese van Groenou MI. Adaptive strategies after health decline in later life: increasing the person-environment fit by adjusting the social and physical environment. European Journal of Aging 2006; 3;169-177.

Woittiez I, Eggink E,Jonker J, Sadiraj K. Vergrijzing, verpleging en verzorging (Population aging, nursing and caring, in Dutch). Sociaal-Culureel Planbureau: The Hage; 2009. 